\title{
ESTIMATIVA DE CUSTOS DE UM \\ EMPREENDIMENTO NAS FASES INICIAIS DE \\ PROJETO: CONTRIBUIÇÃO DO PROCESSO BIM
}

\author{
TAYSE BOTH | UFSC \\ LETICIA MATTANA, M.SC. |UFSC
}

\section{INTRODUÇÃO}

A estimativa de custos nas fases iniciais do processo de projeto é de extrema importância, visto que o estudo de soluções alternativas com base no custo estimado pode viabilizar a execução de empreendimentos.

A indústria da construção civil é um dos setores que mais consome recursos naturais e utiliza energia de forma intensiva, gerando consideráveis impactos ambientais. Dessa forma, é necessária a adoção de práticas e processos produtivos que visam à sustentabilidade. Essas soluções, a princípio, podem ser apressadamente julgadas como dispendiosas, e em uma avaliação empresarial, necessitam de uma análise de viabilidade econômico-financeira para que se decida por sua adoção (AZEVEDO, 2015).

Entretanto, o setor da construção civil brasileira investe pouco nas etapas que antecedem a execução do empreendimento, sendo uma dessas etapas a análise de viabilidade de custos de construção, que contribui para a sustentabilidade econômica das edificações (CARVALHO, 2009). Para auxiliar no processo de tomada de decisão, métodos tradicionais de estimativas de custos foram desenvolvidos, mas em muitos casos, mostram-se insatisfatórios ou pouco efetivos. Sabe-se que o processo de projeto e de orçamentação vem passando por mudanças com a adoção do Building Information Modeling (BIM) pelo setor, o qual dispõe de ferramentas que possibilitam o levantamento de quantitativos a partir de um modelo paramétrico, possibilitando a realização de estudos de viabilidade e orçamentos.

$\mathrm{Na}$ presente pesquisa estudou-se as potencialidades que o BIM oferece para a estimativa de custo nas fases iniciais de projeto, utilizando-se de um caso para estudo de uma edificação residencial unifamiliar da cidade de Biguaçu/SC (Figura 1), com a finalidade de comparar custos diretos através de diferentes métodos: CUB, estimativa de custos no Dprofiler, orçamento executivo e custo real de execução. A metodologia utilizada compreende: (1) investigação das principais ferramentas BIM que contribuem para a estimativa de custos, (2) formatação de um banco de dados de custo no Dprofiler, (3) realização da modelagem volumétrica no Dprofiler, (4) elaboração da estimativa de custos com o auxílio do Dprofiler, (5) desenvolvimento de uma estimativa de custos com base no CUB, e (6) análise documental do custo real da obra e do orçamento executivo.

Como resultado, a pesquisa explorou os variados usos do Dprofiler e constatou que a estimativa de custos nas fases iniciais de projeto com a utilização de BIM apresentou bons resultados, com margens de erro de cálculo baixas em relação ao gasto real de execução, quando comparada a avaliação gerada pelo CUB e ao orçamento executivo da obra.

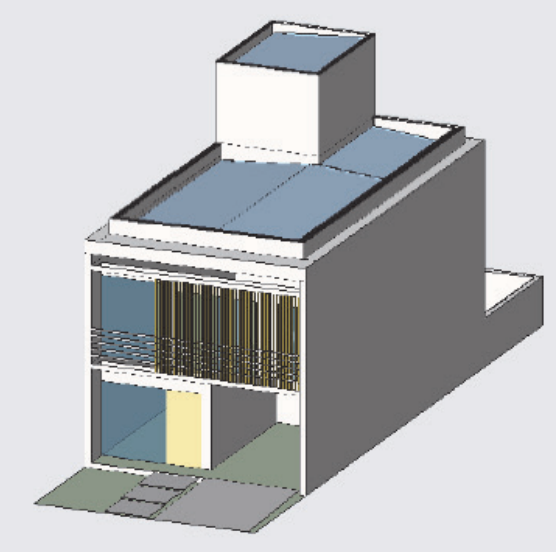

Figura 1 - Modelo Final da Residência Unifamiliar Fonte: Autora (2019)

Conclui-se que a utilização do BIM no processo de estimativa de custos deve ser aplicada pelas empresas responsáveis pelos projetos de arquitetura e engenharia, de forma a auxiliar na otimização dos custos de construção, mas principalmente pelas construtoras e incorporadoras, buscando análises de viabilidade mais precisas. 


\section{REFERÊNCIAS}

AZEVEDO, V. G. C. ; LIMA, F. B. ; VIANA, F. R. A. Análise comparativa técnico-econômica entre empreendimentos com características sustentáveis e convencionais. 2015. Fortaleza. In: Congresso TécnicoCientífico da Engenharia e da Agronomia. Brasília: CONFEA, 2015. v. 1. p. 1-6.

CARVALHO, M T. M. Metodologia para avaliação da sustentabilidade de habitações de interesse social com foco no projeto. Tese de doutorado. Universidade de Brasília, 2009. Brasília, DF, 2009, 241p. 